\title{
Effectiveness of Educational Training related to Disaster Preparedness among Nursing Students
}

\author{
Aftab Ghouri $^{1}$, Badil $^{2}$, Raja ${ }^{3}$, Shaheen Zahir Ali ${ }^{4}$, Abdur Rehman Khan ${ }^{5}$
}

\begin{abstract}
Objective: To evaluate the effectiveness of educational training related to disaster preparedness among nursing students at Karachi

Methodology: This quasi-experimental study was performed in Indus College of Nursing and Midwifery in Karachi. The study was carried out from June to November 2019 over a period of six months. Total sample size was 40. Both male and female final year nursing students were included. The participants were approached by using non-probability purposive sampling method. Validated questionnaire was used to collect the data. Data was entered and analyzed using SPSS version 22.0.

Results: Out of total 40 subjects, 19 (47.5\%) were males. A large number $23(57.5 \%)$ of respondents' ages lied between 23 and 27 years. Nearly half $21(52.5 \%)$ of the participants' educational qualifications were Matriculation. Majority $34(85 \%)$ of participants did not have any formal education of disaster management. On the other hand, few $6(15 \%)$ study participants had training of disaster management. Significance difference was found between pre and post knowledge score of disaster, burns, flood and earthquake practices among study participant and it is also statistically significant.

Conclusion: It is concluded that there is an effect of educational intervention on pre and post knowledge of disaster, burns, flood and earthquake practices among study participants.
\end{abstract}

Key words: Effectiveness, Educational Training, Disaster Preparedness, Nursing Students

How to cite this article: Ghouri A, Badil, Raja, Ali SZ, Khan AR. Effectiveness of educational training related to disaster preparedness among nursing students. Ann Jinnah Sindh Med Uni 2020; 6(2):50-53

DOI: https://doi.org/10.46663/ajsmu.v6i2.50-53

\section{INTRODUCTION}

Disaster is a situation which has severe consequences including disturbance of daily activities, destruction of infrastructure, electricity, roads and loss of lives ${ }^{1-3}$. There are two types of disasters, one is natural and the second is man-made disaster. Natural disasters include floods, droughts, volcanic eruptions, land sliding. While, man-made disasters include accidents, fires,

1 Benazir College of Nursing, Shaheed Mohtarma Benazir Bhutto Medical University, Larkana, Pakistan

2 Institute of Nursing, Dow University of Health Sciences Karachi, Pakistan

3 Department of Plastic and Reconstructive Surgery, Dr. Ruth K.M. Pfau, Civil Hospital, Karachi, Pakistan

4 Indus College of Nursing \& Midwifery, Karachi, Pakistan

5 College of Nursing, Ziauddin University, Karachi, Pakistan

Correspondence: Badil, Assistant Professor, Institute of Nursing, Dow University of Health Sciences Karachi, Pakistan

Email: badil@duhs.edu.pk poisoning, bomb blasts, and industrial accidents etc ${ }^{4}$. Time and place of disaster is unpredictable but the healthcare providers (HCPs) can reduce the number of casualties in a disaster by providing efficient care ${ }^{5}$.

Globally, disaster rate is increasing which ultimately turns focus towards the preparedness of nurses to handle critical situation ${ }^{6}$. So, plans may be developed at nationwide, provincial and local levels for effective disaster response $\mathrm{e}^{7,8}$.

World Health Organization (WHO) reviewed the present situation and sought to improve nursing curriculum by adding management and prevention of disaster ${ }^{9}$. Hence, this education is given by several health agencies to increase competency in disaster relief ${ }^{10}$. Nursing students should be provided sound theoretical and practical knowledge for disaster readiness ${ }^{11}$. In the past, Florence Nightingale also identified this lacking and recommended for education in order to prevent complications ${ }^{12}$. Nurses must be able to observe nursing needs, develop plans, and collaboratively implement this plan within situational context ${ }^{13}$. The competencies of HCPs are measured on the basis of knowledge of skills, implementation of skills, learning attitude of 
individuals and success of institution, hence it explains the behavior of $\mathrm{HCPs}^{14}$.

According to Global Climate Risk Index of Pakistan in 2014, it was reported that Pakistan is on number three across the globe, facing unwanted events of flood and earthquake ${ }^{15}$, which caused destruction with massive casualties and HCPs struggled to provide relief to the people. As a result, lots of gaps were pointed out which need proper planning and preparedness ${ }^{16}$. These kinds of disasters can be handled with collaboration of different organization and illustrate the need of sound knowledge ${ }^{17}$, to build self-confidence for sound decision making in emergency situations ${ }^{18,19}$.

The Pakistan Nursing Council can play a vital role by adding disaster related topics in the curriculum and by encouraging research work at national disaster forum for its effective management ${ }^{20}$. Hence, this study was conducted to evaluate the effectiveness of educational training related to disaster preparedness among nursing students at Karachi.

\section{METHODOLOGY}

This Quasi-experimental study was performed in Indus College of Nursing and Midwifery in Karachi for a period of six months from June to November 2019. Subjects were approached by non-probability purposive sampling method.

The sample size was calculated on STATA 14 software with power $80 \%$, significance level $5 \%$ of previous study pre and post mean and standard deviation $(6.26 \pm 1.61 \& 12.42 \pm 2.45)$ respectively, the required sample size was 4 but as the samples were easily accessible so total sample size was $40^{3}$.

The willing students of final year nursing were included. Written informed consent was obtained from all the participants prior to induction in the study. Ethical approval was taken from Interactive Research \& Development (IRD) with IRD_IRB_2019_07_003. Semi-structured questionnaire was used for data collection. Pilot study was conducted among $10 \%$ of sample size and changes were made as per findings. The questionnaire consisted of 39 questions that covered demographics, flood, earthquake, and burn practice.

A five-day intervention was provided. On the first day, introduction of research objectives, purpose was explained to all research participants, written consents were taken, and pre-test was obtained. On the second and third day of intervention, audio-visual aids were used in lecture for 60 minutes, in which knowledge and practice related to flood, earthquake, burns and first aid management was given and handouts were also distributed. On the fourth day, demonstration and hands-on-practice was performed. On the fifth day, post-test was taken. The questionnaire comprised 6 demographic questions, 8 disaster knowledge, 10 burns practices, 11 flood practices and 10 earthquake practice questions.

The data was entered and analyzed on SPSS version 22.0. Categorical data was managed by frequency and percentage. Whereas mean and standard deviation were computed for continuous data. Knowledge of disaster was assessed by independent $t$-test. While, the difference between pre- and post-knowledge was determined through paired t-test.

\section{RESULTS}

Table 1 exhibits the demographic characteristics of study participants. Out of total 40 subjects, 19 (47.50\%) were males. Large number $23(57.50 \%)$ of respondents' ages were between 23 and 27 years.

Nearly half $21(52.50 \%)$ of the participants' qualifications were matriculation. Majority 34 (85\%) of participants did not have any formal education of disaster management. On the other hand, a few $6(15 \%)$ study participants had training of disaster management.

Table 1: Demographic Information of the Participants

\begin{tabular}{|l|c|c|}
\hline Demographic Factors & $\mathbf{N}$ & $\mathbf{\%}$ \\
\hline Gender & 19 & 47.50 \\
Male & 21 & 52.50 \\
Female & & \\
\hline Age (in Years) & 15 & 37.50 \\
$18-22$ & 23 & 57.50 \\
$23-27$ & 2 & 5.00 \\
\hline Above & & \\
\hline Qualification & 21 & 52.50 \\
Matriculation & 16 & 40.00 \\
FSc & 3 & 7.50 \\
Others & & \\
\hline Formal Education & & \\
in Disaster Management & & 15.00 \\
Yes & 6 & 85.00 \\
No & 34 & \\
\hline
\end{tabular}

Table 2 shows the pre and post-test mean knowledge of disaster, burns, floods and earthquake practices. The pre mean disaster knowledge score was $4.57 \pm 1.12$ while after training post mean disaster knowledge score was $7.30 \pm 0.68$ which is statistically significant (pvalue $<0.001)$. Pre-knowledge about burn practices score was $6.60 \pm 1.614$ and after training post mean 
knowledge of burn practice score was $8.70 \pm 0.88$ which is also statistically significant ( $\mathrm{p}$-value $<0.001$ ). The flood related practices knowledge was assessed and its pre training score was $8.67 \pm 1.89$ whereas post training mean score was $9.32 \pm 1.28$. This variable was also found significant $(\mathrm{p}$-value $=0.021)$. The pre and post knowledge of earthquake practice was also measured, the pre training earthquake score was $5.85 \pm 1.35$ and post training earthquake practice score was $9.20 \pm 0.93$ which is also statistically significant (p-value $<0.001)$.

Table 2: Difference in Pre and Post-Knowledge of Disaster, Burns, Floods and Earthquake Practices

\begin{tabular}{|l|c|c|c|c|}
\hline \multicolumn{2}{|c|}{ Knowledge } & Mean & t-test & p-value \\
\hline Disaster & Pre test & 4.5750 & & \\
& Post test & 7.3000 & -14.929 & $<0.001$ \\
\hline Burn Practice & Pre test & 6.6000 & & \\
& Post test & 8.7000 & -8.396 & $<0.001$ \\
\hline Flood Practice & Pre test & 8.6750 & & \\
& Post test & 9.3250 & -2.414 & 0.021 \\
\hline Earth Practice & Pre test & 5.8500 & & \\
& Post test & 9.2000 & -12.124 & $<0.001$ \\
\hline
\end{tabular}

Table 3 showed gender-wise knowledge difference. It is highlighted that males had more pre-knowledge (mean knowledge 5.05 \pm 1.17 ) as compared to female participants $(4.14 \pm 0.91)$ and it is also statistically significant $(\mathrm{p}-\mathrm{value}=0.009)$. The post training knowledge in males and females is approximately equal, male participants $(7.31 \pm 0.67)$ female participants (7.28 \pm 0.71$)$ and also not statistically significant (pvalue $=0.892$ ) which concludes that there is no mean difference of knowledge among the genders.

Table 3: Gender-Wise Knowledge Difference

\begin{tabular}{|l|l|c|c|c|c|}
\hline Knowledge & Gender & Mean & SD & t-test & p-value \\
\hline Pre-test & Male & 5.052 & 1.177 & & \\
& Female & 4.142 & 0.910 & 2.749 & 0.009 \\
\hline Post-test & Male & 7.315 & 0.671 & & \\
& Female & 7.285 & 0.717 & 0.137 & 0.892 \\
\hline
\end{tabular}

\section{DISCUSSION}

In this study, $52.5 \%$ of the nursing students were females and maximum age was 23-27 years (57.5\%). Similarity was observed with the study of Korean diploma nursing students in which $(98.8 \%)$ were females with 21-25 years range of age ${ }^{21}$. Present study found $85 \%$ of participants had not attended any training previously. Likewise Egypt study also disclosed 88.8\% not having received any formal training ${ }^{22,23}$. Before intervention, the male students' knowledge mean score $5.052 \pm 1.177$ SD was slightly higher than female students $4.142 \pm 0.910$ respectively with significant $\mathrm{p}$ value 0.009 , while female post-test knowledge mean score became approximately equal to male students (M) $7.315 \pm 0.671 \&$ (F) $7.285 \pm 0.717$ individually but statistically no significant p-value 0.892 . On the other hand, a study identified females' pre-knowledge mean score $(6.41 \pm 1.51)$ to be higher than male students $(5.91 \pm 1.81)$ with significant $p$-value $>0.05$ and post score $(12.34 \pm 1.53 \& 12.61 \pm 1.20)$ but $p$-value $>0.05$ was significant in contrast with current study ${ }^{24}$ hence it could be possible that male students have much exposure of dealing with emergencies. Another study reported noticeable difference in pre-test scores $(13.83 \pm 2.26)$ and post-test knowledge scores $(20.16 \pm 2.66)^{25}$. Furthermore, study conducted in Japan also revealed significant difference between pre and post-test score $10.38 \& 14.68$ respectively with 4.29 difference $^{26}$. Additionally, another Korean study exposed similar results as mean score of pre and posttest $10.60 \pm 3.82 \& 19.50 \pm 2.13$ individually with significant p-value $<0.001^{27}$.

Research study presented obvious improvements in mean pre-evaluation and post-evaluation and difference provided in percentage of each item ${ }^{28}$. The present study found knowledge of nursing students regarding earthquake practice mean score as pre $5.850 \pm 1.350$ SD and post $9.200 \pm 0.939$ SD respectively. One study depicted comparable results mean $70.07 \pm 10.01 \mathrm{SD}$ at moderate level ${ }^{29}$. Moreover, another study revealed much difference among pre and post means score $2.18 \pm 0.68$ and $6.30 \pm 0.84$ respectively with significant p-value 0.000 , which is similar to present study ${ }^{30}$.

\section{RECOMMENDATIONS}

1. Educational programmes add essential component for all undergraduates and graduates enhance further their understanding of disaster.

2. To manage the patients in hospital/community setting, the nursing curriculum should be revised and updated with disaster management.

3. More research work is needed to assess the effectiveness of teaching methodology among nurses and nursing students especially in disaster circumstances.

\section{Limitations of the Study}

The study was accomplished in single setting as well as in a private institution with small sample size, hence the findings of the study cannot be generalized. 


\section{CONCLUSION}

Inadequate knowledge of nursing students on disaster prior to interventional session and improvement in knowledge and practice after educational activity reflects significant need for educational programmes to pay more attention to disaster related practices in curricula.

Authors' contribution: AG conceived the idea, B performed statistical analysis and proofreading, $\mathrm{R}$ searched the literature, SZA collected data and performed critical review. ARK collected data. AG, R, and ARK contributed to writing the manuscript.

\section{References}

1. Nash TJ. Unveiling the truth about nurses' personal preparedness for disaster response: A pilot study. Med surg Nurs. 2015;24(6):425-431.

2. Nourbakhsh A, Li Q, Liu X, Shah S. " Breaking" Disasters: Predicting and Characterizing the Global News Value of Natural and Man-made Disasters. arXiv preprint arXiv:170902510. 2017.

3. Sattar SA, Zahra NI, Mohamed WM. The Effect of an Educational Intervention about Disaster Preparedness on Knowledge and Attitudes of Technical Nursing Institute Internnurse Students. Am J Nurs. 2018;7(6):287-295.

4. Karvinen I, Lejonqvist GB, Kinnunen ER, Fredriksson M, Halonen R, Koski A. A study of the community-based disaster preparedness in Kenyan rural communities. Int J Health Syst Disaster Manage.2016;4(3):102-107. DOI: 10.4103/23479019.191103

5. SE G. The Effect of Simulations on Nursing Students' Ethical Reasoning Confidence in Disasters: A Pilot Study.

6. Curriea J, Kourouchea S, Gordona CJ, Jorm CM. Mass casualty education for undergraduate nursing students in Australia. Nurse Edu Prac. 2018; 28:156-62. DOI: 10.1016/j. nepr.2017.10.006.

7. KS R. A study of the community based disaster preparedness in Kenyan rural communities.

8. Maeda T KS, Matsuda N, Edwards GD. Disaster readiness among nurses in Japan: Current status following the Great East Japan earthquake. International J Nurs. 2016; 3(1):1528.

9. Witt RR Gebbie KM. Tailoring curricula to fit health professional's needs in a disaster: a proposal for Brazilian nurses. Rev Gaucha Enferm. 2016; 37(1): http://dx.doi.org/ 10.1590/1983-1447.2016.01.56229

10. Keating E, Edwards F, Sawnson C, Most Effective Interventions for Disaster Relief Preparation. Anna Vaughn Coll Nurs.2018;5:1-27.

11. Nowak M, Fitz Patrick J.J, Schmidt CK, De Ranieri J. Community partnerships: Teaching volunteerism, emergency preparedness and awarding Red Cross certificates in nursing school curricula. Procedia-Soci Behavior Sci. 2015;174:331337. https://doi.org/10.1016/j.sbspro.2015.01.669
12. Cheema AR Mehmood A, Imran M. Learning from the past: analysis of disaster management structures, policies and institutions in Pakistan. Disast Prev Manage. 2016; 25(4):44963. DOI: 10.1108/DPM-10-2015-0243

13. Samar Deen. Pakistan 2010 floods. Policy gaps in disaster preparedness and response. Int J Disast Risk Reduc. 2015; 12:341-9.

14. Kim TE, Shankel T, Reibling ET, Paik J, Wright D, Buckman $\mathrm{M}$, et.al. Healthcare studentsinterprofessional critical event/disasterresponse course. Am J Disaster Med. 2017;1 (12):11-26. doi: 10.5055/ajdm.2017.0254.

15. Evans CA, B-HM, Schwartz R, Veenema T. Nursing Students' Transfer of Learning during a Disaster Tabletop Exercise. Nurse Educ. 2019;44(5):278-283. doi: 10.1097/NNE.0000000000000602.

16. Nilsson J, Eva J, Carlsson M, Florin J, Leksell J, Lepp M, et.al. Disaster nursing: Self-reported competence of nursing students and registered nurses, with focus on their readiness to manage violence, serious events and disasters. Nurse Educ Pract.2016;17:102-8. doi: 10.1016/j.nepr.2015.09.012.

17. Achora S, Kamanyire KJ. Disaster Preparedness: Need for inclusion in undergraduate nursing education. Sultan Qaboos Univ Med J. 2016; 16(1):e15-9. doi: 10.18295/squmj. 2016. 16.01.004.

18. Kim HJ. A study on disaster preparedness, core competencies and educational needs on disaster nursing of nursing students. J Korea Academia-Indust cooper Society. 2015; 16(11):7447-55.

19. Diab GM, Mabrouk SM. The effect of guidance booklet on knowledge and attitudes of nurses regarding disaster preparedness at hospitals. J Nurs Educ Prac.2015;5(9):17-31. DOI: 10.5430/jnep.v5n9p17

20. Gladston S, Nayak R. Disaster Preparedness Among Nurses working in A Paediatric Acute Care Setting of A Tertiary Hospital, South India. IOSR J Nur Health Sci (IOSR-JNHS). 2017; 6(2):55-9. DOI: 10.9790/1959-0602015559

21. Zinan N, Puia D, Kinsley T. Results of a mass casualty incident simulation in an undergraduate nursing program. J Nurs Educ Prac. 2015;5(12):71. DOI: https://doi.org/10.5430 /jnep. v5n $12 \mathrm{p} 71$

22. Ghezeljeh TN, Aliha JM, Haghani H, Javadi N. Effect of education using the virtual social network on the knowledge and attitude of emergency nurses of disaster preparedness: A quasi-experiment study. Nurs Educ Today. 2019; 73:88-93. doi: 10.1016/j.nedt.2018.12.001.

23. Alim S, Kawabata M, Nakazawa M. Evaluation of disaster preparedness training and disaster drill for nursing students. Nurse Educ Today. 2015;35(1):25-31. doi: 10.1016/j.nedt. 2014.04.016.

24. Huh SS, Kang HY. Effects of an educational program on disaster nursing competency. Public health nurs.2019;36(1):2835. doi: 10.1111/phn.12557.

25. Natareno K. Disaster Knowledge and Awareness of Nurses Related to Triage in Mass Casualty Incidents. 5-2018

26. Basnet P, Songwathana P, Sae-Sia W. Disaster nursing knowledge in earthquake response and relief among Nepalese nurses working in government and non-government sector. J Nurs Educ Prac. 2016; 6(11).

27. Kang SJ, Piao MH. The effect of global disaster competency development program on paramedic and nursing undergraduate students. The Korean J Emerg Med Serv. 2014; 18(1):83-94. 